Article

\title{
Remote Laboratories as a Means to Widen Participation in STEM Education
}

\author{
Ian Grout \\ Department of Electronic and Computer Engineering, University of Limerick, Limerick V94 T9PX, Ireland; \\ Ian.Grout@ul.ie; Tel.: +353-(0)61-202-298
}

Received: 16 October 2017; Accepted: 21 November 2017; Published: 23 November 2017

\begin{abstract}
In this paper, a discussion is presented into how remote laboratories can be utilized in STEM (science, technology, engineering, and mathematics) education in order to provide and promote access to laboratory experiments via the Internet. This provision can be considered from a range of viewpoints in how to use Internet-based technologies to allow remote access to physical laboratory experiments whilst taking into account the needs and wishes of the individual. In recent years, countries around the world have placed an increased emphasis on promoting access to education for traditionally underrepresented groups and also to improve the quality of STEM education. Despite this, gaining access to laboratory facilities and experiments for many people can still be a problem. Remote laboratories can, however, be designed, developed, and deployed to support access to STEM education by providing remote access to facilities that would not otherwise be accessible to an individual. Recently, a range of solutions have been developed and successfully deployed which can be used to both provide access to and improve the quality of an educational offering. This paper will consider how the remote laboratory can be developed and used. It can also be considered as an assistive technology which could be used to provide access to individuals with specific needs, such as disability. The paper will consider what a remote laboratory is and how it can be developed with accessibility in mind.
\end{abstract}

Keywords: STEM; education; remote; laboratory; participation; accessibility

\section{Introduction}

Although the provision of universal access to quality education is an important consideration for society, even today not everyone can avail of suitable opportunities to access education at primary, secondary, and tertiary (higher) levels. However, widening participation in education [1,2] is now a priority in many countries in order to facilitate both social and workplace inclusion, and as a driver to support economic growth. Historically, there has always been an imbalance in the representation of different sections of society from undertaking higher level (college and university) education. Some groups have been traditionally underrepresented in higher education due to a range of different reasons. These would include disability, social and economic status, gender, or belonging to an ethnic minority. Today there is a need to ensure that deterrents or barriers to full and effective participation in education are removed. To support access to education, global, national, regional, and individual initiatives have been developed with the aim to break down the access barriers and to promote increased participation in education. For example, considering disability, at an international level the United Nations Convention on the Rights of Persons with Disabilities (CRPD) [3-5] was adopted in New York on the 13 December 2006. The Convention, and its Optional Protocol, entered into force on 3 May 2008. The CRPD is an international treaty and is important as rather than considering disability as an issue of charity, medical treatment, or social protection, the CRPD understands disability as a human rights issue. Individuals are entitled to make personal decisions based on free and informed 
consent, as well as being active members of society. The CRPD covers many areas where obstacles can arise, such as physical access to buildings, roads, and transportation, and access to information through written and electronic communications. The Optional Protocol establishes two procedures aimed at strengthening the implementation and monitoring of the Convention. The importance of the CPRD has also been recognized by the European Union (EU) which has developed a Framework that "promotes, protects and monitors the implementation of the Convention in matters of EU competence" [6]. This Framework became operational in 2013, based on a proposal by the European Commission that was endorsed by the European Council in 2012. In addition, at the international level, The World Health Organization (WHO) [7] identifies that disability is a complex phenomenon and not just a health problem.

Within society, an effective and inclusive education system is a fundamental requirement. However, not everyone is be in a position to avail of many educational opportunities and the opportunities have not been effectively promoted to specific areas of society. In this paper, the discussion will focus on how Internet technologies could be used to support access to education through a remote and online connection. That is, an education resource is made accessible to an individual at a remote location from the resource with the use of an Internet connection. Reference will be made to the use of remote laboratories, how such laboratories are used, and how they can be utilized for users with specific needs, i.e., individuals with disabilities who would need to gain access to engineering or scientific laboratories that may be otherwise inaccessible. Hence, the remote laboratory may be seen as a form of assistive technology and the paper will focus on the technical and usability aspects of remote laboratories.

This paper will be structured as follows: Section 2 will discuss the need to widen participation in education. Section 3 will introduce the idea of the remote laboratory, with reference to example implementations, and Section 4 will propose the remote laboratory as an assistive technology. Section 5 will provide two example remote laboratory interfaces based in different human computer interaction (HCI) scenarios. The aim here is to identify and discuss different ways in which an individual can access remote laboratory resources. Section 6 will provide a discussion based on three questions relating to the use of technology in education: Can we? How do we? Should we? Section 7 will conclude the paper.

\section{Widening Participation in Education}

In recent years, countries around the world have placed emphasis on promoting access to education for traditionally underrepresented groups and improving the quality of STEM education. These would include disability, social and economic status, gender, or belonging to an ethnic minority. However, gaining access to education has been and still is a problem for many people. In engineering and science, the need to access laboratory facilities and experiments can also lead to additional problems. Therefore, supports are required within the education institutions that can reduce the inequality and promote access for all. Promoting access to education can be seen and provided for in a number of different perspectives. Technology plays a critical role in promoting and supporting an individual's access to full education, irrespective of their personal circumstances. This is particularly apparent in the STEM subjects. Technology is now at the center of the learning experience and any barrier to the utilization of the required technology would hinder the individual. For example, in engineering and science education, laboratory-based experiments are a vital part of an education program enabling a reinforcement of theory learnt and the acquisition of practical skills. The traditional "at-presence" laboratory would be physically located within the education establishment and require the individual to attend the laboratory in person. This might not, however, be possible. For example, the location and access routes to the laboratory may mean that it is actually inaccessible to an individual with a mobility impairment. Although the education institution would normally be required to provide access, this would be reliant on whether the inclusion of an access route would be a "fair and reasonable accommodation". For old buildings, access might not, however, be possible and so alternative arrangements would need to be provided, if possible and practical. 
In general, with the move towards widening participation in university-level education and the need to enhance student support for all students, there is a need for higher education institutions, governmental organizations and departments, and non-governmental organizations to develop new, and enhance existing, approaches. To enable this, all relevant stakeholders need to increase their understanding in order to develop new approaches to facilitate widening participation and student support. Table 1 provides additional information on specific European level activities, organizations, and projects that are/were aimed at considering student engagement with a particular focus on disability support. Considering an international context, this table would be significantly increased in size through national-level initiatives.

Table 1. Example of European organizations and projects promoting accessibility in education.

\begin{tabular}{|c|c|}
\hline Resource & Access Details (Accessed on 7 November 2017) \\
\hline $\begin{array}{l}\text { SALEIE-Strategic ALignment of Electrical } \\
\text { and Information Engineering in European } \\
\text { Higher Education Institutions }\end{array}$ & $\begin{array}{l}\text { SALEIE project home page. Available online: } \\
\text { http:/ / www.saleie.co.uk }\end{array}$ \\
\hline $\begin{array}{l}\text { SALEIE project Student and Staff } \\
\text { Support Hub }\end{array}$ & $\begin{array}{c}\text { SALEIE project Student and Staff Support Hub, Hub Style } \\
\text { selection page. Available online: } \\
\text { http://www.saleie.co.uk/SSSH/index.htm }\end{array}$ \\
\hline ENEVA project & $\begin{array}{l}\text { ENEVA project, European Portal of EU projects on disabled } \\
\text { people. Available online: http:/ / www.enevaproject.eu/ }\end{array}$ \\
\hline ELDY—Eldy Association NGO & ELDY. Available online: http:/ / www.eldy.eu/ \\
\hline $\begin{array}{l}\text { ICT4IAL (ICT for Information } \\
\text { Accessibility in Learning) }\end{array}$ & ICT4IAL. Available online: http:/ / www.ict4ial.eu \\
\hline ASSISTID & $\begin{array}{l}\text { ASSISTID homepage. Available online: } \\
\text { http:/ / www.assistid.eu/ }\end{array}$ \\
\hline $\begin{array}{l}\text { Assistive technology projects at the } \\
\text { University of Southampton }\end{array}$ & $\begin{array}{c}\text { E.A. Draffan, University of Southampton, Department of } \\
\text { Electronics and Computer Science. Available online: } \\
\text { http://www.ecs.soton.ac.uk/people/ead }\end{array}$ \\
\hline The European Access Network (EAN) & $\begin{array}{c}\text { European Access Network (EAN). Available online: } \\
\text { http:/ / www.eanedu.org/ }\end{array}$ \\
\hline Access and Inclusion (ACCESS) & $\begin{array}{l}\text { Access and Inclusion (ACCESS). Available online: } \\
\text { http:/ / www.eaie.org/home/about-EAIE/ } \\
\text { expertcommunities/overview/access.html }\end{array}$ \\
\hline $\begin{array}{l}\text { Academic Network of European } \\
\text { Disability experts (ANED) }\end{array}$ & $\begin{array}{c}\text { Academic Network of European Disability experts (ANED) } \\
\text { Available online: http:/ / www.disability-europe.net/ }\end{array}$ \\
\hline $\begin{array}{l}\text { AHEAD—Association for Higher } \\
\text { Education Access \& Disability }\end{array}$ & $\begin{array}{c}\text { AHEAD—Association for Higher Education } \\
\text { Access \& Disability. Available online: http://www.ahead.ie }\end{array}$ \\
\hline
\end{tabular}

Globally, countries have or are developing their own approaches to support and supporting participation with a focus that is specific to the particular country. However, in all cases, then, the core ethos is to reduce, and ultimately remove, inequality, and to support social inclusion for all citizens. The key is to enhance and promote accessibility that includes universal access to education [8]. Aspirations for equality must also be met with appropriate support. For example, a building for everyone approach $[9,10]$ movement looks to ensure that in all aspects of society, buildings, facilities, and services are accessible to all. As an example of a building for everyone approach, the Centre for Excellence in Universal Design in [11] provides a set of documents on building for everyone that is considered in two parts: (i) a universal design approach; and (ii) shared space. The universal design approach is defined here as:

"Building for Everyone: A Universal Design Approach" provides comprehensive best practice guidance on how to design, build and manage buildings and spaces so that they can be readily accessed and used by everyone, regardless of age, size ability or disability [12]. 
Best practice approaches to providing access to all as a natural part of provision is a driving factor. Many of the principles can be applied not only to buildings, but also to education service provision and the right use of the right technology at the right time.

\section{The Remote Laboratory}

Laboratories provide an essential part of the learning experience for engineering and science students. How the laboratory is set up and what experiments are to be undertaken would be dependent on the required learning outcomes set by national level needs, the particular education institution requirements, and the capabilities of the institution. However, the learning experience would need to support the provision for "opportunities to engage in processes of investigation and inquiry" [13]. The laboratory must, therefore, have a purpose and enhance the learning experience. In this section, the remote laboratory $[14,15]$ as one form of laboratory setup is discussed.

Remote laboratories are physical laboratories that allow access to experiments within the laboratory by users who would not be in the same physical location as the experiment.

A remote user would access the experiment with a virtual presence using a suitably-designed computer-based user interface since they would not be able to physically interact the laboratory equipment. This remote user would also be a form of virtual student [16] (i.e., has a virtual presence in the classroom/laboratory) and typically, the laboratory user interface is based on a web page. A user can navigate to the remote laboratory web page using a suitable web browser and, with certain restrictions, access the laboratory on an "as and when" arrangement. Different remote laboratories provide different user interfaces, a range of specific experiments and different access arrangements. An experiment could be operated on a continuous (24/7) basis and allow one or more users to access a single experiment by use of the Internet. This means that a remote user, for example in Australia, could access a remote experiment on the other side of the world, for example in Ireland, without any problems due to time zone differences and physical distance. Such laboratories can then provide access to experiments and laboratory equipment that would not be otherwise accessible. The location of the experimenter is not an issue for gaining access to the experiment, provided that access to a suitable computing platform and an Internet connection was available. In addition, the experimenter can be supported to undertake an experiment within a required time period or could access the experiment at times that supported their personal circumstances.

\subsection{The Remote Laboratory as an Educational Resource}

The remote laboratory should be seen as an educational resource and one possible form of laboratory. Table 2 identifies a classification of laboratories based on experimenter location and the type of experiment undertaken.

Table 2. Classifying laboratories.

\begin{tabular}{|c|c|c|c|}
\hline \multirow{4}{*}{$\begin{array}{c}\text { Experiment Type } \\
\text { Real (physical) } \\
\text { Virtual (simulated) }\end{array}$} & \multirow{2}{*}{$\begin{array}{c}\text { Local Experimenter } \\
\text { (Same Location as the Experiment) } \\
\text { Local }\end{array}$} & \multicolumn{2}{|c|}{$\begin{array}{l}\text { Remote Experimenter } \\
\text { (Different Location from the Experiment) }\end{array}$} \\
\hline & & \multicolumn{2}{|c|}{ Remote } \\
\hline & At-presence (physical) & Remote laboratory & Hybrid \\
\hline & At-presence (simulated) & Virtual laboratory & \\
\hline
\end{tabular}

The classification is based on whether the experimenter is local to the experiment (traditional, experimenter is physically in the same laboratory as the experiment- "at-presence") or remote (different location and access is via an Internet connection-"remote") and whether the experiment is a real physical experiment or a software simulation of the real physical experiment. For remote locations, the laboratory would be defined as remote (real experiment), virtual (simulation), or hybrid 
(the laboratory supports both real and simulation experiments). Whilst this paper identifies a differentiation between remote and virtual, the terms are sometimes used to mean the same thing, and so the detail implementation of the laboratory and its available resources need to be understood.

A local laboratory setup provides an additional benefit to the student in that there is direct and immediate access to the educators and technical support within the laboratory. In addition, the ability to interact with other students to discuss ideas and solve problems together can be beneficial to many students (the development of social skills in a professional work environment), particularly where group project work is undertaken. Having remote access to an experiment removes that direct contact and early remote laboratories may now be seen as limited in that they were based on a single student accessing the experiment without contact with other people. This contact limitation problem is not so much of an issue today with the capabilities of online tools, such as discussion boards, video conferencing, and even some social media platforms, which can be integrated into the experiment setup and a community of online and remote experimenters established where appropriate. This global community would be able to interact with the experiments, as well as other learners in a manner that is established by the laboratory supporters: educators, moderators, and technical support.

Figure 1 shows how these remote laboratories could be connected to users and the users supported to interact with each other. Multiple remote experimenters are connected to the Internet and can access a remote laboratory using a web browser of choice (typically Microsoft Internet Explorer, Microsoft Edge, Google Chrome, Mozilla Firefox, Apple Safari and Opera Software Opera). The experimenter would know the URL (Uniform Resource Locator) (or the IP (Internet Protocol) address) of the remote laboratory and when laboratory web site is visited, a suitably-designed web page would guide the experimenter to access and use the laboratory experiments and documentation (resources). Typically, the first step would be to log into the laboratory using a username/password arrangement which would give access to specific resources such as a range of experiments, documentation, and instructions on how an experiment can be used. Before any log-in can be attempted, the laboratory administrator would establish who can access the laboratory, when access would be available, and what resources are available to each user. Therefore, there would be a significant amount of effort by the laboratory developer and administrator to create the right system for the user before the laboratory could be used.

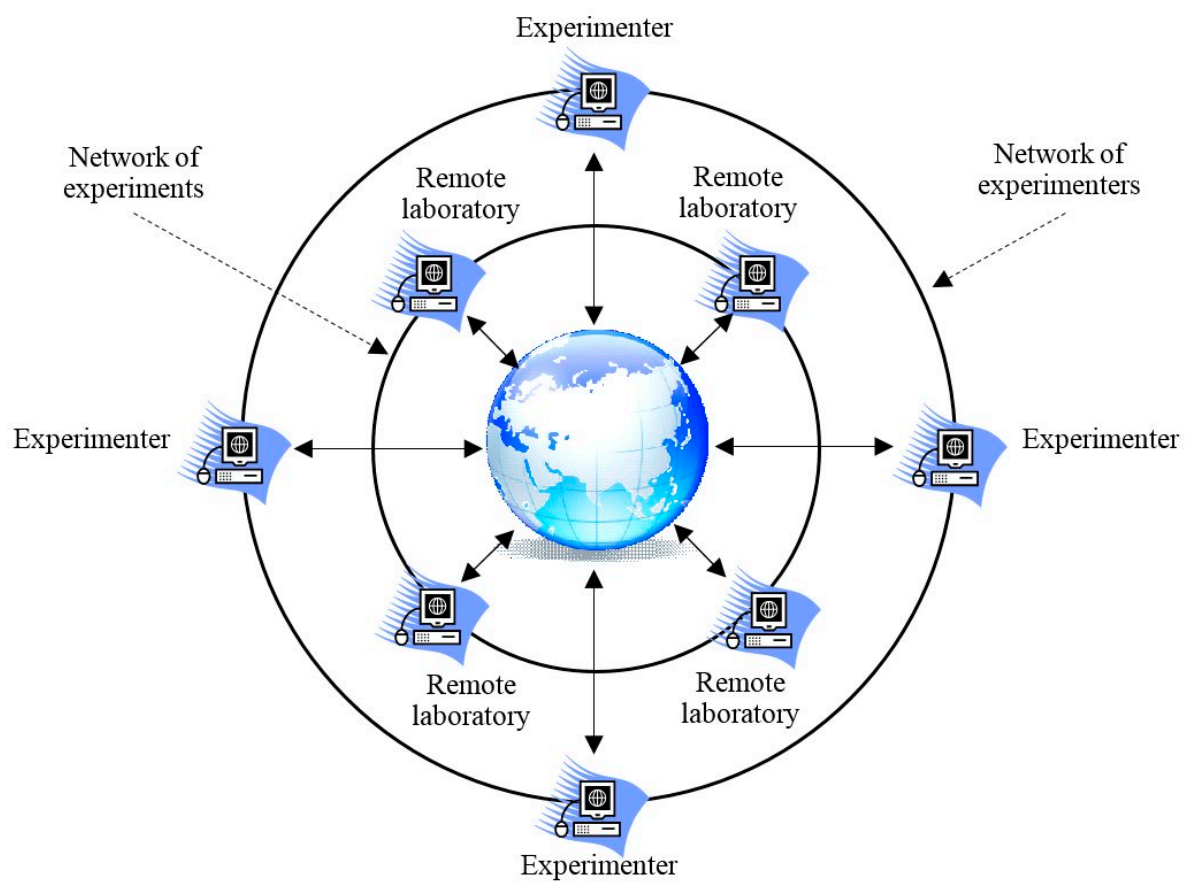

Figure 1. A global online and remote laboratory community. 
Where multiple users would have access to multiple experiments, a suitable protocol would need to be developed in order to control access since multiple users could not access the same experiment at the same time. Who accesses what experiments and at what time(s) can be established by controlling access to a user:

- Based on a timetable where the user selects (books) the experiment on a particular day and for a particular period of time through a booking system:

- This allows for immediate control of the experiment and the experiment responds to the user commands with only a delay due to network delays as the experiment is dedicated to that user;

- Such an approach is suitable for situations such as robotics based experiments where a user would need to control the experiment with minimal time delay.

- By using a queue-based system where a user submits their inputs to the laboratory and the user request is placed in a queue:

- The laboratory responds to each request in turn. However, there would be a delay due to queue processing and so would be suitable for situations where a time delay is not an issue.

\subsection{Laboratories in Education}

The laboratory in engineering and science education is a vital part of an education program. What emphasis is placed on the laboratory as compared to theoretical knowledge acquisition would be dependent on the particular country level and institutional level requirements and capabilities. The laboratory provides a number of key activities that include:

- Reinforcement of theory learnt;

- Acquisition of practical skills;

- "Opportunities to engage in processes of investigation and inquiry" [13];

- Development of social skills;

- Development of individual and team working skills;

- Use of specific equipment and software tools that are relevant to the "world of work" post-graduation;

- Supporting the required learning outcomes;

- Improving the quality of the education provision.

Figure 2 aims to illustrate the above points when considering the role of the laboratory in education. The figure considers the different components in a laboratory teaching and learning scenario. The people are the students and staff (academic, teaching assistants, technicians, administrators) who collaborate within the laboratory environment. Ideally, the needs for all students should be taken into account. The physical infrastructure is the laboratory itself (physical building (access to and internal), along with the furniture, lighting and heating). The standard laboratory equipment is the equipment used in the laboratory, but is not specifically designed to act as an assistive technology (AT). The assistive technologies are the technologies that certain students use whilst within the physical infrastructure in order to undertake their studies. For example, AT is used by students with disabilities to support their studies within a specific learning environment. Examples of AT include audio and video recording and playback devices. The learning material is the laboratory notes and supporting material (in audio and visual formats) which the student uses to complete the laboratory experiments and assignments. However, the creation and use of the laboratory may not always be possible from both the learner and the institution perspectives:

- Laboratory equipment can be expensive and not available to some education institutions. Purchasing equipment, maintenance, training, support, and cost of use can be prohibitively expensive or not available in regions of the world, such as many developing countries; 
- For some, a physical or mental impairment may preclude them from gaining access to a laboratory as it might be inaccessible or not set up for their particular needs. Whilst it is important to identify that education institutions would aim to make provisions for the individual, in some cases then a "fair and reasonable accommodation" would not be possible to make;

- Financial aspects mean that an individual might not be able to physically attend the laboratory due to commitments, such as work or being a caregiver for another person.

Therefore, a flexible approach to laboratory provision that can take into account the needs of the individual and the institution whilst maintaining or enhancing the quality of the education provision can be considered. With the rapid increase in the use of Internet technologies and the increase in digital literacy in society, the role that technology plays in education today means that the best that technology can offer can then be used to improve education. However, it is possible that technology can change too quickly and become too complex for many people to use. In an extreme case, the technology could actually hinder, rather than help, the individual. Therefore, care must be taken to ensure that the right technology is used in the right place and for the right reasons. For example, whilst the trend in computing is for mobile platforms using smart phones, the display size and touch screen requirements might create a difficult or frustrating experience for some people. If this type of platform is the only way to access the resource, it could then be argued that the technology then prevents people from accessing the resource, rather than supporting, hence, leading to isolation.

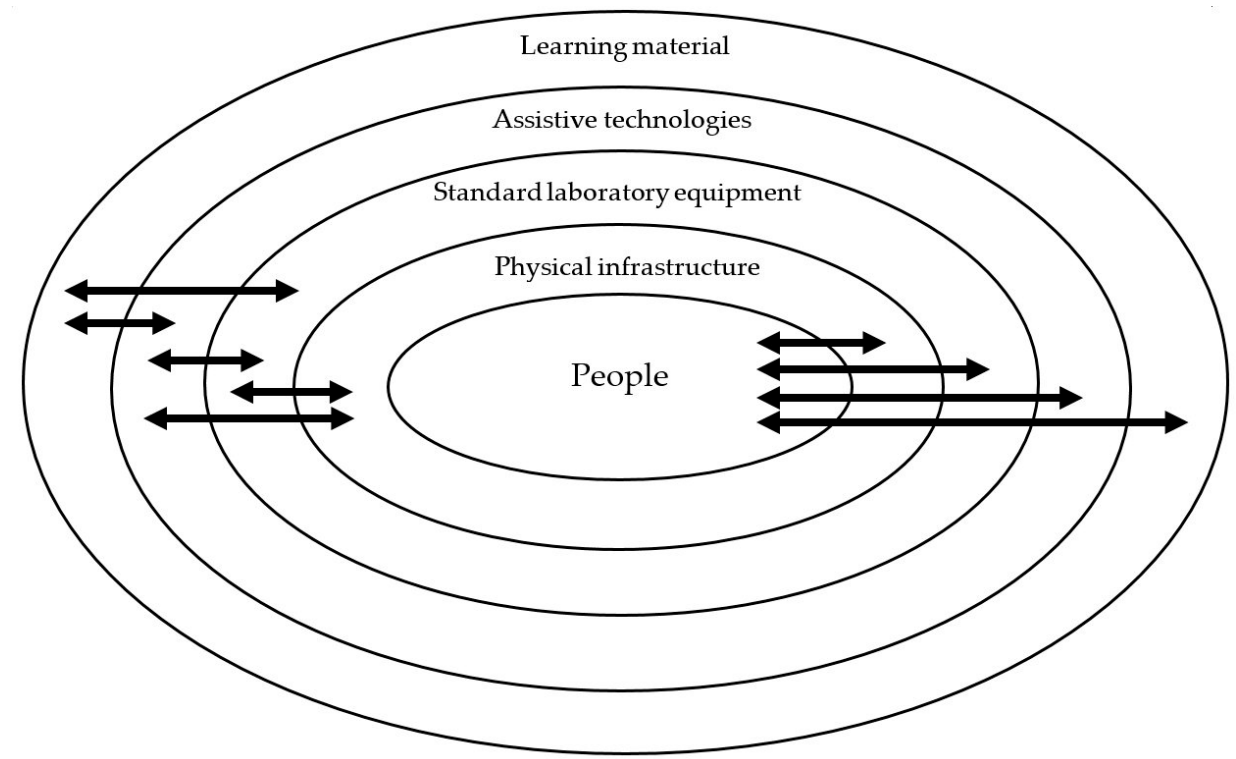

Figure 2. Interactions within the laboratory in education.

\subsection{Structure of the Remote Laboratory}

A remote laboratory must be capable of providing a learning experience that enhances the existing learning experience and provides added value to a study program. In some situations, it can be used to supplement an at-presence laboratory for local students. In other situations, it may provide for access to laboratory equipment and experiments that do not exist within the education institution. However, it should not be considered as a "low cost" replacement of an at-presence laboratory since the role of technology should be to support and enhance the learning experience rather than finding a way to simply reduce costs. Whilst the remote laboratory might initially seem to be a "low-cost" alternative, there is the cost of design, development and maintenance to consider. Hence, each type of laboratory, with reference to Table 2, provides for a unique set of advantages and disadvantages.

With the remote laboratory, the initial steps to creating a remote laboratory that is both useable and useful involve the identification of the intended uses, the target audience, the technologies to use, 
and the integration of the laboratory into a program of study. This might involve the integration of the laboratory into a suitable learning management system (LMS) or access to a content management system (CMS). When considering the architecture of the remote laboratory, it is useful to develop the architecture to meet both the current needs and potential future uses. Adopting such an approach would reduce the need for major effort in any future development work. As an example, Figure 3 shows the structure of a possible hybrid laboratory. Multiple remote users can have access to the experiments using a login/password arrangement. In this case, the need to consider security aspects, such as HTTPS (Hyper Text Transfer Protocol Secure) rather than HTTP may be required as HTTPS provides encrypted data transfer to prevent interception of data transferred between the user and the laboratory. The laboratory connects to the Internet using a computer that acts as the web server.

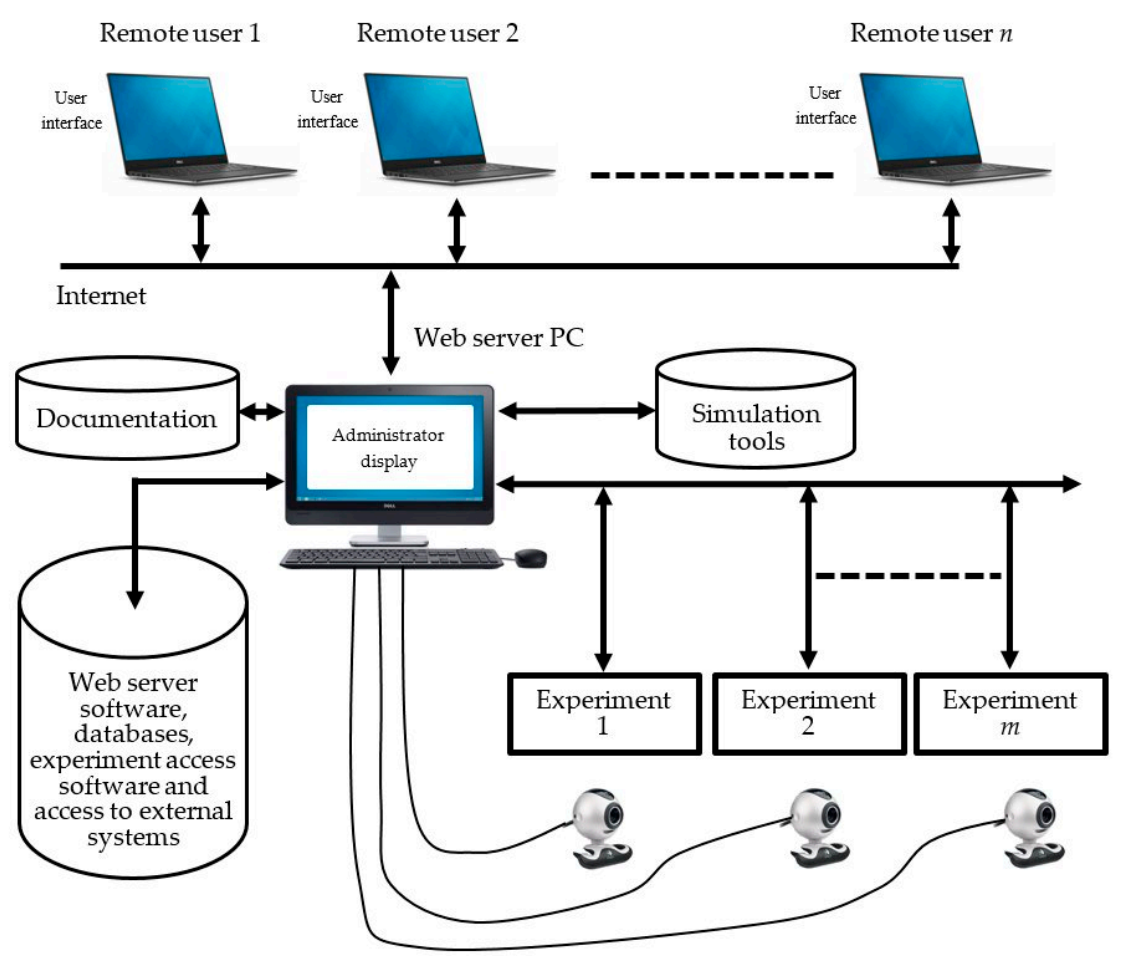

Figure 3. Simplified structure of a hybrid laboratory (a remote and virtual laboratory).

This computer runs a web server software application and has a unique IP address to which it responds. Typically, an Apache HTTP Server (HTTPD) [17] is used and, in many cases, the XAMPP Apache Distribution [18] is preferred. In addition, the web server computer will run one or more databases (typically based on MySQL [19]), software applications to control the experiments and software that will enable the laboratory to talk to other systems, such as other remote laboratories and an LMS or CMS. There will be one or more experiments connected to the computer either using a wired (e.g., Universal Serial Bus (USB)) or wireless (e.g., WiFi, Bluetooth or Zigbee) connection. To enable visual feedback of the experiment in operation, a webcam can be incorporated, as this would give the remote user an understanding that they are using a real, physical experiment rather than interacting with a simulation model. For a hybrid laboratory, the user would also have access to simulation tools in order to run simulation studies from a remote location.

Whilst the above description has considered a setup based on a web server, such as Apache, alternative approaches are used with success. For example, LabVIEW Web Services [20] from National Instruments (NI) allows a person who is familiar with LabVIEW to create a LabVIEW application and deploy it as a web service. Here, the developer creates a LabVIEW VI (virtual instrument) and the user accesses this using a web browser or other web client. Over the last number of years, particularly 
since the 1990s, the gathering interest in online learning and supporting ways in which to engage individuals in the online learning experience has led to the availability of resources to support the developer and user communities. Table 3 identifies a number of useful resources which are provided for further reading and understanding.

Table 3. Online resources: associations, books, journals, and conferences.

\begin{tabular}{|c|c|c|}
\hline Title & Type of Resource & $\begin{array}{c}\text { Further Information URL (Accessed on } \\
16 \text { October 2017) }\end{array}$ \\
\hline $\begin{array}{l}\text { International Association of } \\
\text { Online Engineering (IAOE) }\end{array}$ & Association & http://online-engineering.org/ \\
\hline $\begin{array}{c}\text { The Virtual Student, A Profile } \\
\text { and Guide to Working with } \\
\text { Online Learners }\end{array}$ & Book & $\begin{array}{l}\text { http://eu.wiley.com/WileyCDA/ } \\
\text { WileyTitle/productCd-0787964743.html }\end{array}$ \\
\hline $\begin{array}{l}\text { Using Remote Labs in Education. } \\
\text { Two Little Ducks in } \\
\text { Remote Experimentation }\end{array}$ & Book & $\begin{array}{l}\text { http://www.deusto-publicaciones.es/ } \\
\text { index.php/main/categoria/41/en }\end{array}$ \\
\hline $\begin{array}{l}\text { Advances on Remote } \\
\text { Laboratories and } \\
\text { e-learning experiences }\end{array}$ & Book & $\begin{array}{l}\text { http://www.deusto-publicaciones.es/ } \\
\text { index.php/main/categoria/41/en }\end{array}$ \\
\hline $\begin{array}{l}\text { IT Innovative Practices in } \\
\text { Secondary Schools: } \\
\text { Remote Experiments }\end{array}$ & Book & $\begin{array}{l}\text { http://www.deusto-publicaciones.es/ } \\
\text { index.php/main/categoria/41/en }\end{array}$ \\
\hline $\begin{array}{l}\text { Internet Accessible Remote } \\
\text { Laboratories: Scalable } \\
\text { E-Learning Tools for } \\
\text { Engineering and } \\
\text { Science Disciplines }\end{array}$ & Book & $\begin{array}{l}\text { https: } \\
\text { //www.igi-global.com/book/Internet- } \\
\text { accessible-remote-laboratories /52730 }\end{array}$ \\
\hline $\begin{array}{l}\text { Remote Laboratories for } \\
\text { Teaching and Training } \\
\text { in Engineering }\end{array}$ & Open Access Book Chapter & $\begin{array}{l}\text { https://www.intechopen.com/books/ } \\
\text { design-control-and-applications-of- } \\
\text { mechatronic-systems-in-engineering/ } \\
\text { remote-laboratories-for-teaching-and- } \\
\text { training-in-engineering }\end{array}$ \\
\hline $\begin{array}{l}\text { International Journal of } \\
\text { Online Engineering (iJOE): } \\
\text { ISSN: 1861-2121 }\end{array}$ & Journal & http://online-journals.org/i-joe \\
\hline $\begin{array}{l}\text { REV: International Conference } \\
\text { on Remote Engineering and } \\
\text { Virtual Instrumentation }\end{array}$ & Conference & $\begin{array}{l}\text { http://www.rev-conference.org/ } \\
\text { REV2018/cfp_rev2018.php }\end{array}$ \\
\hline $\begin{array}{l}\text { ICL: International } \\
\text { Conference on Interactive } \\
\text { Collaborative Learning }\end{array}$ & Conference & http://www.icl-conference.org/icl2017/ \\
\hline $\begin{array}{c}\text { IMCL: International } \\
\text { Conference on Interactive } \\
\text { Mobile Communication, } \\
\text { Technologies and Learning }\end{array}$ & Conference & $\begin{array}{l}\text { http:/ / www.imcl-conference.org/ } \\
\text { imcl2017/index.php }\end{array}$ \\
\hline
\end{tabular}

\subsection{Examples of Remote Laboratories}

Since the 1990s, universities and companies have been actively developing remote and virtual laboratories. University based laboratories were in many cases developed from within an engineering department as the core development skills are based on electronic and computer engineering and information technology (IT) subjects. It was typical that the laboratory was then developed for a specific subject or purpose and independently from other laboratory developers. This has resulted in a range of different laboratories, experiments and access methods. The iLabs project [21], for example, from the Massachusetts Institute of Technology (MIT), was the early pioneer of the remote laboratory through 
the development of the iLabs shared architecture (ISA). Table 4 identifies example remote laboratories used by education institutions around the world. A review of relevant conferences and journals, with reference to Table 3, would identify additional examples developed by institutions globally for their own particular requirements.

Table 4. Example reported remote laboratories.

\begin{tabular}{|c|c|c|}
\hline Remote Laboratory Name & Developed by & $\begin{array}{c}\text { Online Information } \\
\text { (Accessed on } 16 \text { October 2017) }\end{array}$ \\
\hline iLabs & $\begin{array}{l}\text { Massachusetts Institute } \\
\text { of Technology }\end{array}$ & http://icampus.mit.edu/projects/ilabs/ \\
\hline WebLab-Deusto & University of Deusto & http://weblab.deusto.es/website/ \\
\hline $\begin{array}{l}\text { VISIR (Virtual Instrument } \\
\text { Systems in Reality) }\end{array}$ & $\begin{array}{l}\text { Blekinge Institute of } \\
\text { Technology (BTH) }\end{array}$ & http://www2.isep.ipp.pt/visir/ \\
\hline $\begin{array}{l}\text { The Grid of Online Lab Devices } \\
\text { Ilmenau "goldi-labs.net" [22] }\end{array}$ & $\begin{array}{l}\text { Technische Universität Ilmenau } \\
\text { (TU Ilmenau) }\end{array}$ & http://goldi-labs.net/ \\
\hline NetLab [23] & University of South Australia & http://netlab.unisa.edu.au/index.xhtml \\
\hline Remote Labs & $\begin{array}{c}\text { University of } \\
\text { Technology Sydney }\end{array}$ & https://remotelabs.eng.uts.edu.au/ \\
\hline Lab Share & The Labshare Institute & https://remotelabs.eng.uts.edu.au/ \\
\hline UNILABS & $\begin{array}{l}\text { Consortium of } \\
\text { universities in Spain }\end{array}$ & http://unilabs.dia.uned.es/ \\
\hline $\begin{array}{l}\text { Internet Accessible } \\
\text { Remote Laboratories }\end{array}$ & Northern Illinois University & http://niu.edu/remotelab/ \\
\hline
\end{tabular}

\section{The Remote Laboratory as an Assistive Technology}

Over the last number of years, there has been an increase in the availability of online courses and programs for distance based learning that are now more than simply "making lecture notes available on the World Wide Web (WWW)". The introduction and evolution of such courses/programs also means that the profile of the student who would be studying online with a virtual presence is changing and different from a traditional at-presence student. The needs for this virtual student [16] and the ability to deliver the right content and in an appropriate manner are important aspects to take into consideration. For example, the student has specific needs, as well as attributes. A suitable set of attributes, such as an individual who is not hindered by the absence of cues, both auditory and visual, that would be present in an at-presence learning scenario, would be required. It also requires the individual to be self-motivated and self-disciplined, and capable of working alone. However, the virtual student would normally work both as an individual and in online groups through suitable online collaborative environments using selected communication tools. Their studies would then be undertaken as part of an online learning community and would collaborate according to the rules of the community. In many cases, the community would use a mix of tools, both those used by the education provider and also those provided through social media. However, there is always the need to consider data security and online safety, and to ensure that everyone involved abides by the rules of the community, adhere to national laws and with respect to others within the community. When considering the use of the remote laboratory in education, the user accesses the experiment from a remote location and has a virtual presence in the laboratory. This remote experimenter has particular needs and attributes which need to be considered. A model for a typical experimenter could be created and the remote laboratory designed with this typical profile in mind. However, the laboratory design should also take into account that the individual may also have specific disability or age related needs and so, the profile now becomes more complex. A "one size fits all" approach to content delivery may not necessarily be appropriate. Hence, the remote laboratory may then need to be developed and 
deployed to enable adaptation to the individual and a customized user interface may be a solution that fits the individual user:

The remote laboratory design and operation should take into consideration the needs of all potential users rather than developing a single "one size fits all" solution that would be suited to what is perceived as a typical student.

\subsection{Accessibility}

As a remote laboratory is an online education resource, the needs of the individual should also be accounted for when designing and integrating the remote laboratory into an education program. One part of the laboratory experience is the web page interface. The question "how accessible is the web site", however, needs to be asked? Additionally, if necessary, "how can a web page be designed or adapted to be accessible"? Accessibility for web sites means that the web site is accessible by all potential users. To support this need, standards have been developed and deployed which aim to enable web site developers to create accessible web pages. The World Wide Web Consortium (W3C) provides guidelines and standards through the Web Accessibility Initiative (WAI) [24]:

1. W3C Web Accessibility Initiative, WAI Guidelines and Techniques [25];

2. Web Content Accessibility Guidelines (WCAG) 2.1 [26].

The Web Accessibility Initiative (WAI) develops strategies, guidelines, and resources to help make the Web accessible to people with disabilities. At the heart of the initiative is to enable web content to be accessible by all potential users. The WCAG were developed through the W3C process in cooperation with individuals and organizations world-wide. Its goal has been to create a single shared standard for web content accessibility that "meets the needs of individuals, organizations, and governments internationally".

An additional useful resource that was developed is the British Broadcasting Corporation (BBC) set of web accessibility guidelines and standards. Although this resource has now been archived by the $\mathrm{BBC}$, MyWeb my way $[27,28]$ is still accessible online and provides guidelines for developing web sites and defines accessibility as:

Accessibility is the word used to describe whether a product (for example, a website, mobile site, digital TV interface or application) can be used by people of all abilities and disabilities.

In addition, computer operating systems today come with accessibility options. Table 5 identifies accessibility resources for the most popular operating systems. Hence, given that the ability exists to develop customized approaches to accessing an online resource, the remote laboratory can be developed so that a core set of operations can be accessed in different ways using customized user interfaces. The remote laboratory could then be seen as a form of assistive technology (AT). There are a number of ways to define AT. For example, the National Disability Authority of Ireland defines AT as:

The field of Assistive Technology (AT) concerns the practical tools that can support functional needs of people who experience difficulties linked to disability or ageing. It encompasses a broad spectrum of low tech and high tech technologies, for example, walking frames, wheelchairs, hearing aids, vision aids and computer-based communication aids [29].

The right AT can provide major benefits to an individual. However, as specific AT is particular to a need or set of needs, in a broad sense then AT can be considered as suited for:

- Visual impairments;

- Hearing impairments;

- Learning impairments;

- Mobility impairments. 
Table 5. Example operating system accessibility resources.

\begin{tabular}{|c|c|c|}
\hline Operating System & Resource & Further Information URL (Accessed on 16 October 2017) \\
\hline \multirow[t]{3}{*}{ Microsoft Windows } & Windows accessibility & https://www.microsoft.com/en-us/accessibility/windows \\
\hline & Assistive Technology Partners & $\begin{array}{l}\text { https:/ / www.microsoft.com/en-us/accessibility/assistive- } \\
\text { technology-partners? } \mathrm{v}=\mathrm{t}\end{array}$ \\
\hline & $\begin{array}{l}\text { Windows } 10 \text { free upgrade } \\
\text { for customers who use } \\
\text { assistive technologies }\end{array}$ & $\begin{array}{l}\text { https://www.microsoft.com/en-ca/accessibility/ } \\
\text { windows10upgrade }\end{array}$ \\
\hline \multirow[t]{3}{*}{ Apple iOS } & Apple, Accessibility & https://www.apple.com/accessibility/ \\
\hline & Apple, Accessibility on iOS & https://developer.apple.com/accessibility/ios/ \\
\hline & $\begin{array}{l}\text { Apple, Use Accessibility } \\
\text { features on your iPhone, iPad, } \\
\text { and iPod touch }\end{array}$ & https://support.apple.com/en-us/HT204390 \\
\hline \multirow[t]{2}{*}{ Android } & Android Central, Accessibility & https://www.androidcentral.com/accessibility \\
\hline & $\begin{array}{l}\text { Android Central, Basic } \\
\text { accessibility settings in Android }\end{array}$ & $\begin{array}{c}\text { https: / /www.androidcentral.com/basic-accessibility- } \\
\text { settings-android }\end{array}$ \\
\hline
\end{tabular}

\subsection{Examples of Assistive Technology}

Impairments may be due to disability or age and a suitable AT can be selected for a specific need or needs. AT does necessarily not need to be "high-tech" that would be typically based on software programmed electronic hardware. For example, a walking stick would be considered "low-tech", but is a suitable AT for some forms of mobility impairment. Hence, the choice of AT needs to be carefully considered and meet the end-user requirements. Examples of AT that may be or are used in an education setting include:

- Speech recognition software (e.g., Dragon Speech Recognition Software [30]);

- $\quad$ Screen reading software (e.g., Windows Narrator [31]);

- Wearable electronics [32] (e.g., The Autism Glass Project at Stanford Medicine [33]);

- Screen magnifiers;

- Mathematical language and symbol reader software with audio output (e.g., Mathjax [34]);

- Smart pens that record everything that is heard, said, and written, and links audio recordings to notes (e.g., the Livescribe Smartpen [35]).

Selecting and deploying AT for an individual needs careful consideration so that the right technology is selected, training in the use of the selected AT is provided and support available once the technology has been deployed. The choice of which AT would be most appropriate would be made by a team of professionals and consultants trained to match particular AT to the specific needs of the user. This is undertaken in consultation with the user and should have the user at the center of all decision-making. An AT team may include, for example, doctors, regular and special education teachers, speech-language pathologists (SLPs), and occupational therapists.

Given that the remote laboratory could be set-up with accessibility as a major consideration and the laboratory interface could be customized to the needs of an individual, the remote laboratory could be considered as a form of AT.

Accessibility can be built in by developing a customized user interface for each user. This interface would interact with a common framework for all users. This customization would consider both the access method (how to input commands and data) and how to receive the experiment results.

\section{Customizing a Remote Laboratory User Interface for Accessibility}

The standard approach for an individual to access the remote laboratory is via a desktop PC, laptop PC, or smartphone (mobile computing for mobile learning scenarios) with a web browser 
display. The input devices are the keyboard, mouse, touchpad, or touchscreen and the output device is the visual display unit (VDU). These are forms of human computer interface (HCI) [36,37] and would be the most familiar devices to most people. Commands and experiment data are entered into the web page as a combination of keyboard (text) entries, mouse movement or clicks, or touch/swipe actions on a touchscreen. The response of the experiment is viewed on the VDU, either as text, tables, images or animation. HCI considers the design and use of computer technology with a focus on the interfaces between people (the users) and computers. HCI is sometimes also referred to as human-machine interaction (HMI) and covers a broad range of technical and non-technical considerations. When considering laboratory accessibility, alternative forms of input and output can be considered that replace devices, such as the keyboard, mouse, touchpad, or touchscreen. An appropriate device or set of devices could then be integrated into the user side of the laboratory to form a customized user interface. These would include devices that would be familiar to computer games players and include:

- Non-contact hand position, motion and gestures;

- Head position, motion and gestures;

- Eye position, motion and gestures;

- Joystick;

- $\quad$ Speech (voice recognition);

- Brain activity;

- Tactile displays;

- Audio messages;

- Images and animation rather than text based information.

In addition, interaction can also be supported with the aid of Virtual Reality (VR) headsets and Augmented Reality (AR) displays. In a remote laboratory, it would be possible to implement the above solutions to act as alternative input-output devices that would replace the keyboard, mouse or touchscreen. Figure 4 depicts how a customized interface can be used within a remote laboratory set-up.

Essentially, the user would have a customized (personalized) user interface that is suited to their particular needs. This would need to be initially set-up and calibrated for the user. The input device would mimic specific operations of a keyboard-mouse arrangement and, so, a software application running on the user's computer would automatically provide this functionality. The amount of functionality possible would depend on the interface design and how it would be used. The complexity of the interface device (both in the design and use) can vary, based on particular usage scenarios and needs. It is not always necessary to create a technically complex device with extensive user functionality and, in some situations, a simple interface might be more applicable.

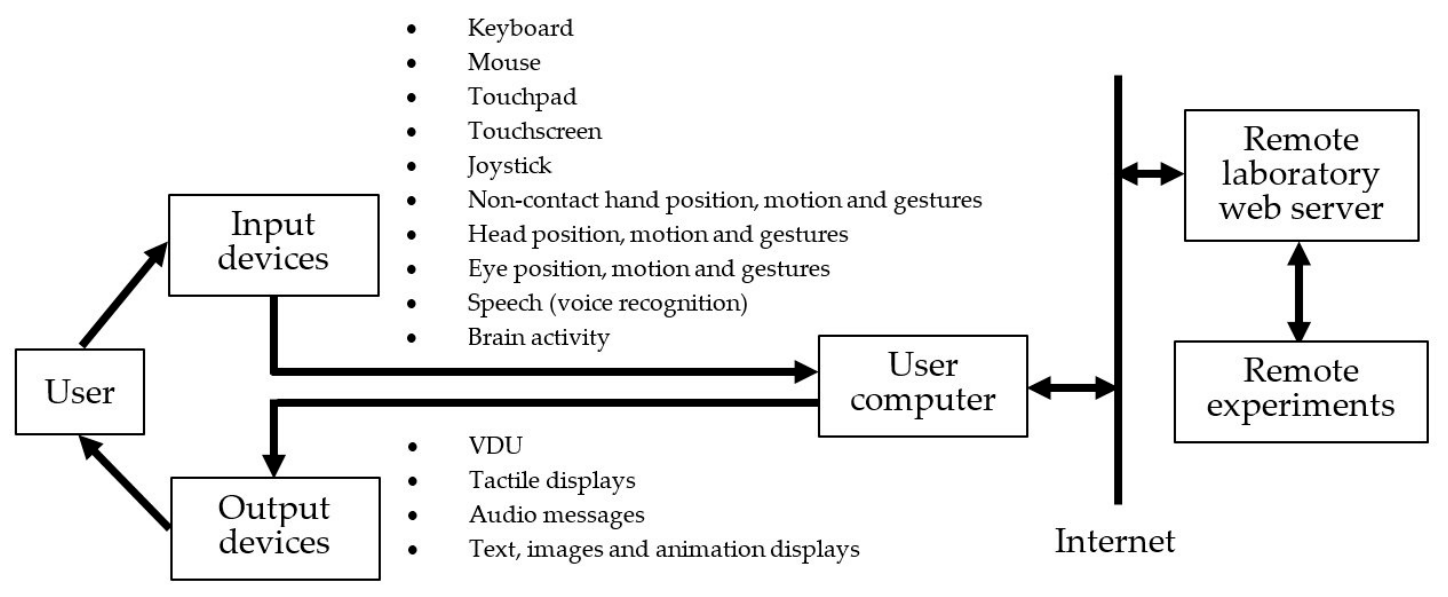

Figure 4. Customizing the remote laboratory interaction. 


\subsection{Example 1: Hand Motion and Sensor Plate}

This example considers a simple contactless approach to controlling the computer application and hence to send commands and data to the remote laboratory with the use of hand positions. Figure 5 shows the interface which is based on a microcontroller circuit with a USB (wired) connection to the computer. On the printed circuit board (PCB, left), six Hall Effect sensors (S1 to S6) in a $2 \times 3$ array [38] react to a hand passing over a sensor. The microcontroller sends the sensor readings to the user computer and the sensor values are interpreted in order to send specific commands or data to the PC. In this approach, the sensor array mimics keys on the keyboard and if the web page is designed correctly, the user can run an experiment through hand motions and without the need for a keyboard. The hand position is sensed as the user would wear a band (or glove) with an embedded magnet that activates a sensor when it passes over the sensor (right).

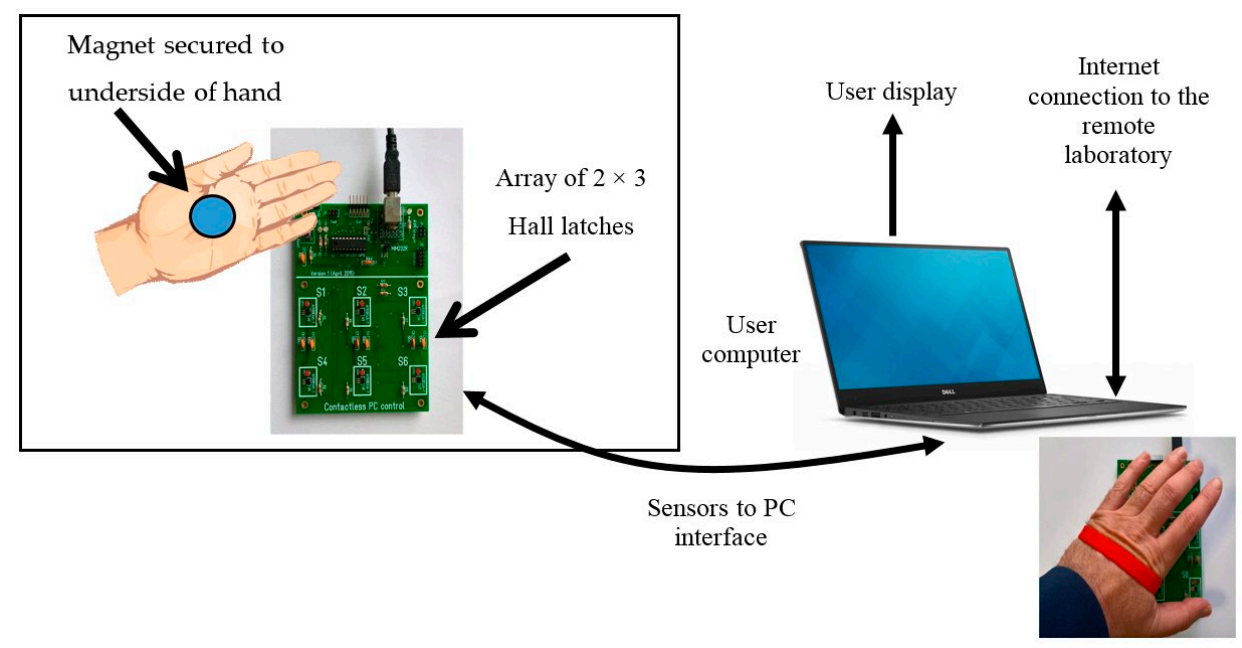

Figure 5. Example 1: sensor plate.

With this arrangement, the user only needs to move his or her hand in small motions over the sensor array area and so:

- $\quad$ Large hand movements are not required;

- $\quad$ Fine motor dexterity is not required;

- The sensor readings can be made tolerant to motion impairments such as hand tremors;

- There is no need to physically touch any equipment, such as power supply control buttons and dials, or the PC keyboard/mouse arrangement.

Although this interface has a reduced functionality when compared to the keyboard and mouse, it may be that its simplified use would be better in some scenarios where only a few user options could be used to guide the user through a menu of options leading to the required outcomes.

\subsection{Example 2: Leap Motion Controller}

This example considers an alternative form of contactless interface that is based on hand position, motion and gestures as shown in Figure 6. The Leap Motion Controller [39] is a device that connects to the USB port of a computer and allows for interaction with a computer by hand position, motion, and gestures. Hence, a computer can be controlled without the use of a traditional keyboard, mouse or touchscreen. The Leap Motion Controller is a form of NUI (natural user interface). The controller can be placed on a suitable surface, for example on a desktop, but not necessarily a horizontal surface. It can also be mounted to a VR headset and allows a user to move their hands in front of their body to undertake actions in scenarios such as VR games. Figure 6 shows the controller and its use with a laptop computer. This would 
allow a user to move their hand(s) above the controller and the hand position, motion, and gestures can be used to control a computer application. By writing a suitable computer application to read in the positions, motions and gestures, a form of non-verbal language can be developed and the computer application would react to these as user commands or data.

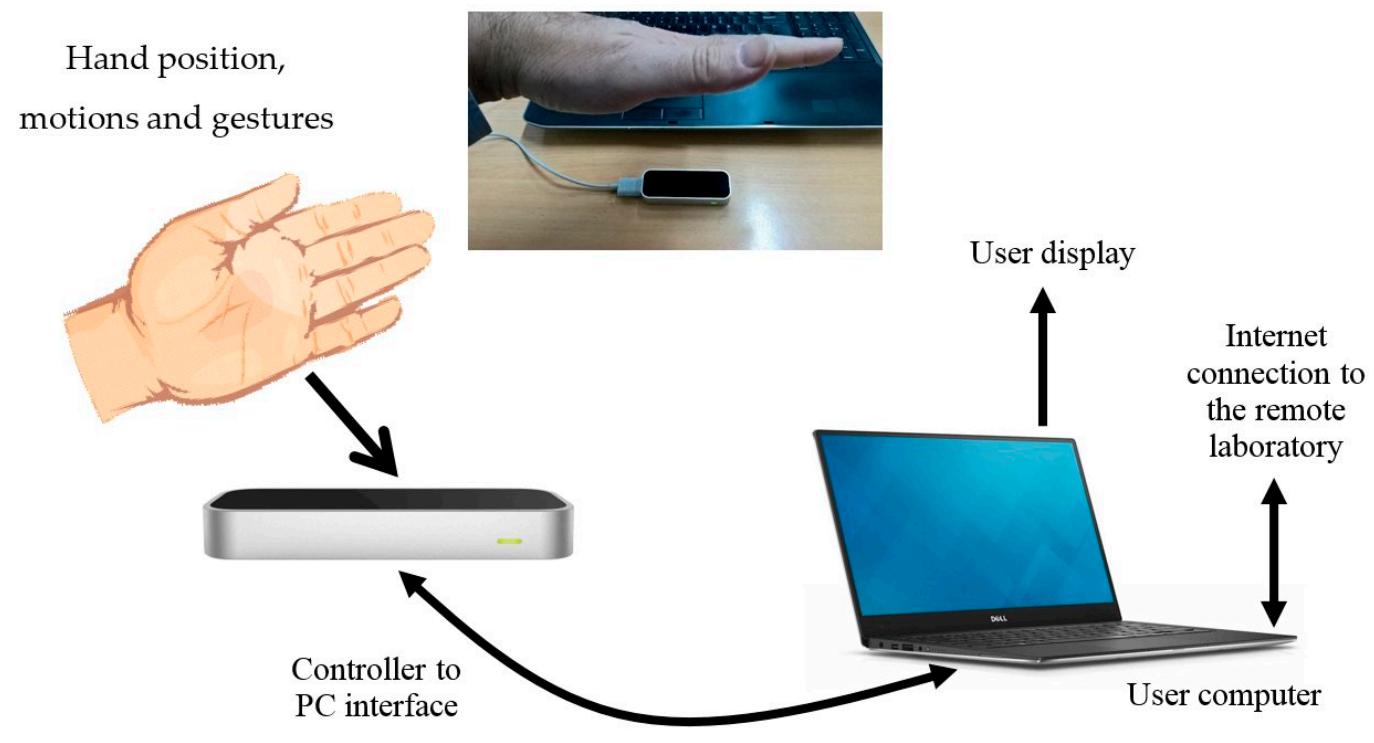

Figure 6. Example 2: Leap Motion Controller.

In a remote laboratory scenario, rather than using a keyboard/mouse arrangement, the user can undertake hand motions and gestures that are natural to create and these motions/gestures form a non-verbal language that the remote laboratory understands. Such a language can be unique to an individual and so, the same equipment can be used by different users by personalizing the language to the user. With this arrangement, the user only needs to move his or her hand in small motions over the sensor array area and, so, the same benefits as the previous example (in Section 5.1) can also be applied. This is a more advanced system than the previous system and would require more design development and training than the previous system. Hence, an approach with different levels of complexity and use can, therefore, be deployed based on an assessment of the user needs and the scenario(s) in which the system is to be used.

\section{Use of Technology in Education}

Technology has an important and sometimes essential role in education. The benefits of technology inclusion in the learning experience may enhance the existing learning experience for many, and be the only way in which to engage for others. With the increased use of the Internet within education, communities of online learners can engage in a wide variety of beneficial activities. This includes the provision of learning material which were available in early online forms using CMSs, and more commonly now within LMSs. However, accessibility for all is not always a primary design consideration for the CMS or LMS but, with increased learner requirements and national level legislation requirements, accessibility is becoming an important driving factor. Recent developments have also seen the development of MOOCs (massive open online courses) [40] which are programs of study made available over the Internet without charge to a very large number of people. MOOCs can be seen as an evolution of open courseware (materials used by educational institutions made available on the Internet) and have the aim to provide large-scale interactive participation and open access in study programs via the WWW. A recent addition to the online portfolio has been the introduction of the concept of the MOOL (massive open on-line laboratory) [41]. 
The range of possible technological solutions to the education access problem therefore has many possible approaches. However, considering all aspects, whilst some solutions can be beneficial, other solutions may not. It is not simply the idea of "bringing technology into the classroom" and there would be questions that can be asked. Three such questions in relation to remote laboratories would be: Can we? How do we? Should we?

- Can we? Can we use the remote laboratory in education? The answer is yes, and there would be good reasons that allows for an increase in participation. The available remote laboratories have been developed with specific requirements in mind and these have been based on identified learning outcomes. Where there is a sound academic reason to introduce new technology, this should be fully supported and encouraged. The design of the experiments should be undertaken in order to enhance the learning experience.

- How do we? The first step is that there must be a solid motivation and intent to design, develop, and deploy one or more remote laboratories that would be fully supported by the education institution. The experiments available would need to enhance the existing education experience and must have a sound pedagogical basis. Ideally, a multi-disciplinary team consisting of engineers, IT specialists, pedagogical specialists, and institutional management/administration would be required to ensure a successful outcome. The motivation should be widening participation rather than reducing laboratory running costs (i.e., the inclusion of technology is seen simply as an accounting exercise). Finally, the laboratory should be embedded into the target programs and study, have academic and technical support, and the enterprise should be seen as a long-term student support improvement project.

- Should we? A difficult, but important, question to ask. Introducing technology just "because we can" should not be a motivation and the user of this educational resource should be at the center of all decision-making. This means that the resource access requirements for all students need to be taken into account and the necessary training in order to use the technology must be provided. Suitable resource documentation and support once deployed must be developed prior to introduction and use best practice approaches to technology and education. A cautious, but optimistic, approach would need to be adopted in order to create a successful laboratory implementation.

\section{Conclusions}

This paper has considered the role of the remote laboratory in education and how such a laboratory can be designed and deployed in STEM education. The structure and operation of typical remote laboratories was discussed with reference to example solutions. This is a form of education technology that can be beneficial in specific teaching and learning scenarios. An increasingly important aspect for the educator and education institution is how to increase the accessibility of the educational offering, targeting traditionally underrepresented groups. This requires the modes of education delivery and provision of information to take the needs of the individual into account and to customize the user experience to the needs of the individual. The remote laboratory, provided that is in an accessible form, can be used to support access to education and to enhance an educational offering. The role of the remote laboratory as an assistive technology was discussed and ideas developed to demonstrate how the remote laboratory user interface can be adapted to support different user needs.

Acknowledgments: This work was supported under the EU Lifelong Learning Programme "SALEIE", project reference No. 527877-LLP-1-2012-1-UK-ERASMUS-ENW.

Conflicts of Interest: The author declares no conflicts of interest. 


\section{References}

1. Oireachtas Library \& Research Service, Ireland. Spotlight, Higher education in Ireland: For Economy and Society? No. 5 of 2014. July 2014. Available online: https://www.oireachtas.ie/parliament/media/ housesoftheoireachtas/libraryresearch/spotlights/Spotlight_higher_education_for_upload_155719.pdf (accessed on 10 October 2017).

2. Pathways to Education Connections Conference 2010. Access: Are We Making the Right Connections. Conference Publication. July 2011. Available online: https:/ /www.esri.ie/pubs/jacb201173.pdf (accessed on 10 October 2017).

3. United Nations. Convention on the Rights of Persons with Disabilities (CRPD). Available online: https: / /www. un.org/development/desa/disabilities/convention-on-the-rights-of-persons-with-disabilities.html (accessed on 10 October 2017).

4. United Nations. Convention on the Rights of Persons with Disabilities-Articles. Available online: https:/ / www.un.org/development/desa/disabilities/convention-on-the-rights-of-persons-with-disabilities / convention-on-the-rights-of-persons-with-disabilities-2.html (accessed on 9 October 2017).

5. United Nations. Optional Protocol to the Convention on the Rights of Persons with Disabilities. Available online: https: / /www.un.org/development/desa/disabilities / convention-on-the-rights-of-persons-withdisabilities / optional-protocol-to-the-convention-on-the-rights-of-persons-with-disabilities.html (accessed on 9 October 2017).

6. European Commission. EU Framework for the UN Convention on the Rights of Persons with Disabilities. Available online: http:/ / ec.europa.eu/social/main.jsp?catId=1189\&langId=en (accessed on 10 October 2017).

7. World Health Organization. Disabilities. Available online: http://www.who.int/topics/disabilities/en/ (accessed on 10 October 2017).

8. Organisation for Economic Co-operation and Development (OECD). Education at a Glance: OECD Indicators 2012, EUROPEAN UNION. Available online: https:/ / www.oecd.org/edu/EAG2012\%20-\%20Country\% 20note\%20-\%20European\%20Union.pdf (accessed on 12 October 2017).

9. National Disability Authority (Ireland). Building for Everyone. Available online: http://www.nda.ie/ cntmgmtnew.nsf/0/EBD4FB92816E8BB480256C830060F761?OpenDocument (accessed on 12 October 2017).

10. Centre for Excellence in Universal Design. Shared Space. Available online: http:/ /www.universaldesign.ie/ sharedspace (accessed on 12 October 2017).

11. Centre for Excellence in Universal Design. Available online: http://www.universaldesign.ie/ (accessed on 12 October 2017).

12. Centre for Excellence in Universal Design. Building for Everyone. Available online: http:/ / www.universaldesign. ie/buildingforeveryone (accessed on 12 October 2017).

13. Hofstein, A.; Lunetta, V.N. The Laboratory in Science Education: Foundations for the Twenty-First Century; Wiley Periodicals Inc.: Oxford, UK, 2003; Available online: http:/ / onlinelibrary.wiley.com/doi/10.1002/sce. 10106/epdf (accessed on 12 October 2017).

14. Zutin, D.G.; Auer, M. A simple LabVIEW based framework to facilitate the deployment of iLab batch lab servers. In Proceedings of the 11th International Conference on Remote Engineering and Virtual Instrumentation (REV), Porto, Portugal, 26-28 February 2014; pp. 328-331. [CrossRef]

15. Cooper, M.; Ferreira, J.M. Remote Laboratories Extending Access to Science and Engineering Curricular. IEEE Trans. Learn. Technol. 2009, 2, 342-353. [CrossRef]

16. Palloff, R.M.; Pratt, K. The Virtual Student-A Profile and Guide to Working with Online Learners; Jossey-Bass: San Francisco, CA, USA, 2003; ISBN 0-7879-6474-3.

17. Apache. HTTP Server Project. Available online: https://httpd.apache.org/ (accessed on 12 October 2017).

18. Apache Friends. XAMPP Apache + MariaDB + PHP + Perl. Available online: https://www.apachefriends. org/index.html (accessed on 12 October 2017).

19. Oracle, Mysql. Available online: https://www.mysql.com/ (accessed on 7 November 2017).

20. National Instruments. LabVIEW Web Services FAQ. Available online: http://www.ni.com/white-paper/ 7747 /en/ (accessed on 12 October 2017).

21. Massachusetts Institute of Technology. iLabs. Available online: http://icampus.mit.edu/projects/ilabs / (accessed on 12 October 2017). 
22. Henke, K.; Vietzke, T.; Hutschenreuter, R.; Wuttke, H.D. The Remote Lab Cloud "goldi-labs.net". In Proceedings of the 2016 13th International Conference on Remote Engineering and Virtual Instrumentation (REV), Madrid, Spain, 24-26 February 2016; pp. 37-42. [CrossRef]

23. Teng, M.; Considine, H.; Nedic, Z.; Nafalski, A. Current and Future Developments in the Remote Laboratory NetLab. Int. J. Online Eng. 2016, 12. [CrossRef]

24. W3C Web Accessibility Initiative. Available online: http://www.w3.org/WAI/ (accessed on 12 October 2017).

25. W3C Web Accessibility Initiative (WAI), WAI Guidelines and Techniques. Available online: http:/ / www.w3. org/WAI/guid-tech.html (accessed on 12 October 2017).

26. W3C. Web Content Accessibility Guidelines (WCAG) 2.1. Available online: http://www.w3.org/TR/WCAG21/ (accessed on 12 October 2017).

27. BBC Web Accessibility, My Web My Way. Available online: http://www.bbc.co.uk/accessibility/ (accessed on 12 October 2017).

28. BBC My Web My Way. BBC Accessibility Policy. Available online: http://www.bbc.co.uk/accessibility/ best_practice/policy.shtml (accessed on 12 October 2017).

29. National Disability Authority of Ireland. Research on the Provision of Assistive Technology in Ireland. Available online: http:/ / nda.ie/Policy-and-research/Research/Research-Publications/Research-on-theprovision-of-Assistive-Technology-in-Ireland.html (accessed on 9 November 2017).

30. Nuance Communications, Inc. Dragon Speech Recognition Software. Available online: https://www.nuance. com/dragon.html (accessed on 12 October 2017).

31. Microsoft. Hear Text Read Aloud with Narrator. Available online: https://support.microsoft.com/en-us / help/17173/windows-10-hear-text-read-aloud (accessed on 12 October 2017).

32. Google. Glass Explorer Edition, Design before You Develop. Available online: https:/ / developers.google. com/glass / (accessed on 12 October 2017).

33. Stanford University. The Autism Glass Project at Stanford Medicine. Available online: http://autismglass. stanford.edu/ (accessed on 12 October 2017).

34. Mathjax. Available online: https://www.mathjax.org/ (accessed on 12 October 2017).

35. Livescribe, Inc. Livescribe Smartpen. Available online: https://www.livescribe.com/en-us/smartpen/ (accessed on 12 October 2017).

36. Sears, A.; Jacko, J.A. Human-Computer Interaction Fundamentals; CRC Press: Boca Raton, FL, USA, 2009; ISBN $1420088815,9781420088816$.

37. Microsoft. Being Human-Human-Computer Interaction in the Year 2020. Available online: http:/ / research. microsoft.com/en-us/um/cambridge/projects/hci2020/downloads/BeingHuman_A4.pdf (accessed on 12 October 2017).

38. Grout, I. Remote laboratories to support electrical and information engineering (EIE) laboratory access for students with disabilities. In Proceedings of the 25th Annual EAEEIE Conference, Cesme, Turkey, 30 May-1 June 2014. [CrossRef]

39. Grout, I.A. Hand Motion and Gesture Control of Laboratory Test Equipment Using the Leap Motion Controller. In Proceedings of the 19th International Conference on Image Analysis and Recognition (ICIAR 2017), Bangkok, Thailand, 29-30 November 2017.

40. Daradoumis, T.; Bassi, R.; Xhafa, F.; Caballé, S. A Review on Massive E-Learning (MOOC) Design, Delivery and Assessment. In Proceedings of the 8th International Conference on P2P, Parallel, Grid, Cloud and Internet Computing, Compiegne, France, 28-30 October 2013; pp. 208-213.

41. Salzmann, C.; Gillet, D.; Piguet, Y. MOOLs for MOOCs: A first edX scalable implementation. In Proceedings of the 13th International Conference on Remote Engineering and Virtual Instrumentation (REV), Madrid, Spain, 24-26 February 2016; pp. 246-251.

(C) 2017 by the author. Licensee MDPI, Basel, Switzerland. This article is an open access article distributed under the terms and conditions of the Creative Commons Attribution (CC BY) license (http://creativecommons.org/licenses/by/4.0/). 